THURMOND, J. B., \& ALLUISI, E, A. Effects of two task variables on the visual perception of form. Joumal of Engineering Psychology, 1965. 4, 101-107.

THURMOND, J. B., \& ALLUISI, E, A. An extension of the information-deductive analy sis of form. Psychonomic Science, 1967, 7, 157-158.

\section{NOTES}

1. Supported in part by the U.S. Army Medical Research and Development Command, Department of the Army, under Contract No. DA-49. 193-MD-2567, "Behavioral Effects of Infectious Diseases." The author wishes to thank Thomas $K$ Dempsey, George W. Menzer, and Thomas J. Rebbin for technical assistance. An abridged report of this research was presented at the 60th annual meeting of the Southern Society for Philosophy and Psychology, April 1968, Louisville, Kentucky.

2. The histoform data reported here were obtained as part of a previously reported study (cf. Thurmond, in press). They are based on the responses of the $60 \mathrm{Ss}$ (12 in each of the five difficulty conditions) who were administered a nonrotated choice-figure condition first as part of a two-part test.

3. The within-cells variances of the measures were not homogeneous according to the test of homogeneity employed here and throughout the study, the technique of Odeh \& Olds (1959). Transformations of the data were not performed: rather, it was decided to rely on the characteristic robustness of the analysis of variance. This procedure was deemed necessary to avoid introducing complications of interpretation, particularly since the interaction of figure type and level of discrimination difficulty $w$ as of primary interest. Based on the Norton study of hypothetical skewed populations with unequal variances, Lindquist (1956) has concluded that even marked heterogeneity of variances produces only a negligible effect on the F-ratio distribution, and that the small effects of such heterogeneity on the probability of Type-l errors might be compensated for by the selection of a slightly smaller alpha Accordingly, Lindquist's sugge stion has been followed wherever nonhomogeneity of variance has been discovered, i.e., in these case s the $1 \%$ confidence level has been required for "statistical significant" rather than the 5 c level.

\title{
Failure to replicate a reported U-shaped visual masking function
}

\begin{abstract}
CHARLES W. ERIKSEN and PHILIP $H$. MARSHALL, University of Illinois, Urbana, III. 61801
\end{abstract}

An attempt was made to replicate a nonmonotonic visual backward masking function that had been reported by Kolers (1962). Neither the replication nor several variations yielded any suggestion of a nonmonotonic masking function. The failure to replicate was attributed to the difference in indicator methodology employed by Kolers and that used in the present study.

A model based upon a Rashevsky. Landahl neural net has been proposed by Weisstein (1968) to describe the temporal course of visual masking. A primary purpose of the model appears to be to describe or account for U-shaped or nonmonotonic masking functions. However, there is some real question as to whether nonmonotonic masking fucntions exist independent of artifacts arising from a confounding of masking with a delayed indicator role of the masking stimulus, indicator methodology that confuses sensitivity with aS's criterion, and/or apparent movement phenomena (Kahneman, 1967).

A major portion of the evidence for nonmonotonic masking functions comes from an experiment by Weisstein (1966). In this experiment multielement displays were employed and the masking stimulus not only served a function as a mask but also indicated to $S$ which element of the display he was to report. As Eriksen, Collins, \& Greenspon (1967) have pointed out, the resulting data represent a composite of two separate processes: a masking function per se and a function describing the decay of the icon due to the delay of the indicator telling $S$ which element to report. By appropriately manipulating constants for these two separate functions a composite curve of widely varying characteristics can be obtained.

Data reported by Kolers (1962) and Kolers \& Rosner (1960) have been widely cited as indicating nonmonotonic backward masking functions. In these studies, how. ever, a target detection or identification criterion was not employed. Instead $\mathrm{S}$ was allowed to adopt his own criterion as to the target's presence or absence and as noted elsewhere (Eriksen \& Collins, 1965), the internal consistency of the data (Kolers \& Rosner, 1960) suggests that S's criterion was extremely variable.

Nonmonotonic backward masking functions typically have not been obtained in recent masking experiments but because of their potential importance to theoretical accounts of masking it is important to determine not only whether they do exist but if they do, the specific circumstances under which they are obtained. We have been singularly unsuccessful in obtaining such functions in our own research and as a first step in an attempt to understand why, we decided to closely replicate the conditions under which other investigators have obtained these nonmonotonic functions.

One of the most pronounced nonmonotonic masking functions in the literature is given by Kolers (1962, Fig. 8) in which the target stimulus was a black-on-white dise subtending $30 \mathrm{~min}$ of angle and exposed for $50 \mathrm{msec}$. The mask was a black-on-white ring subtending $36 \cdot \mathrm{min}$ inner diam with a wall 19-min thick exposed for $100 \mathrm{msec}$ at in terstimulus intervals (ISIs) ranging from 5 to $100 \mathrm{msec}$. As reported by Kolers (1962) maximum masking occurred at an ISI value of $50 \mathrm{msec}$ where the probability of reporting the target disc was only about one-third as great as when the ISI was 5 or $100 \mathrm{msec}$. We attempted to duplicate his conditions in all essentials except that instead of using a modified quantal method (Kolers \& Rosner, 1960) we employed a two-temporal interval forced-choice indicator method. As in Kolers' experiments (Kolers, 1962; Kolers \& Rosner, 1960) viewing was monocular, but instead of always using a 3-mm artificial pupil as Kolers (1962) had done, most of our observations were collected without the artificial pupil. Pilot observations had shown that the artificial pupil did not affect the shape of the function

\section{SUBJECTS}

Six University of Illinois undergraduates, three females. served as paid volun teers. APPARATUS

AND STIMULUS MATERIALS

The stimuli were drawn with black India ink on white matte plastic cards. The discs subtended $30 \mathrm{~min}$ of visual angle. Three rings of the following dimensions were used: i.d., $36 \mathrm{~min}$, wall, $19 \mathrm{~min}$; i.d., $30 \mathrm{~min}$, wall, $25 \mathrm{~min}$; i.d., $45 \mathrm{~min}$, wall, $7 \mathrm{~min}$. A three-field Scientific Prototype Model $320 \mathrm{GA}$ tachistoscope was employed but the original equipment lamps had been replaced with Sylvania F4T5/CWX bulbs. A Macbeth illuminometer was used to calibrate and monitor intensity of the stimulus fields. The adaptation field was maintained at a luminance of $4.5 \mathrm{~mL}$ and the target and masking fields were $5.0 \mathrm{~mL}$. A black " $\mathrm{x}$ " subtending 12 min of angle, was located slightly below the center of the adaptation field and served as a fixation point. The adaptation field was illuminated at all times other than when the target or masking fields were on. The stimuli were always presented 


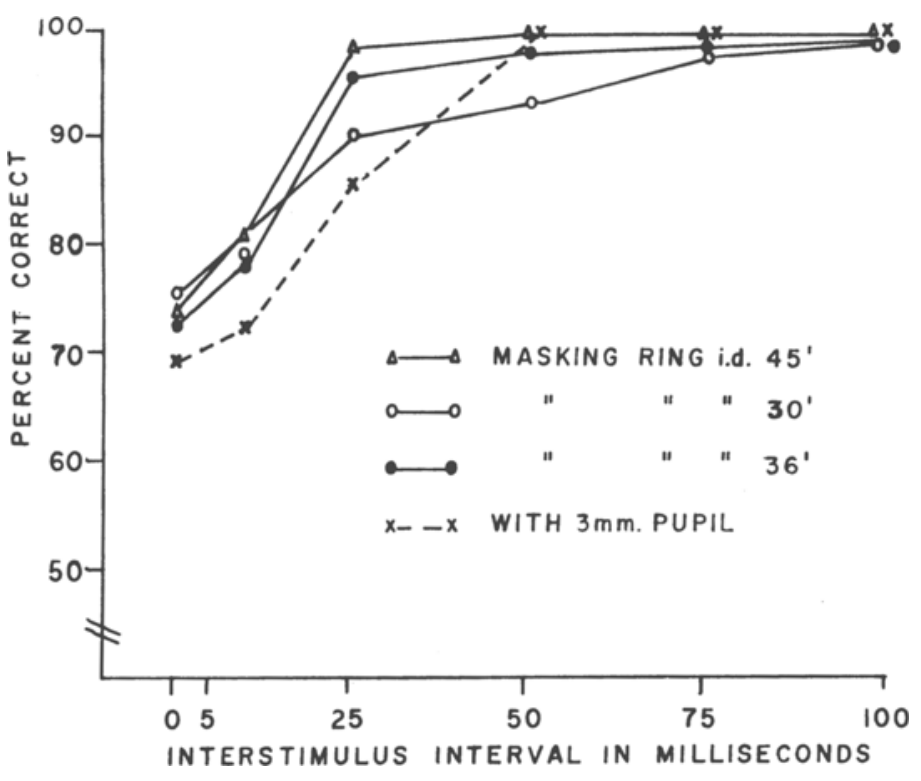

Fig. 1. Per cent correct disc detections as a function of ISI and masking ring size.

in the center of the field and the ring masking stimulus was located so as to center on the disc.

The Ss were divided into three groups of two Ss each for the purpose of assessing the effects of the three ring sizes. Prior to the beginning of an experiment all Ss were given at least three 45-min practice sessions. During these sessions a stable exposure duration for the disc was determined that yielded approximately $75 \%$ accuracy in the detection of the disc when it was immediately followed ( 0 -msec ISI) by the masking ring to be used with that particular S. These exposure durations ranged from 4 to $16 \mathrm{msec}$ across Ss. Following Kolers (1962), the masking ring had a constant duration of $100 \mathrm{msec}$.

A two-temporal interval forced-choice me thodology was used. Each trial consisted of two presentations of the masking ring, on one of which the ring was preceded by the disc. After the two presentations $S$ was forced to choose in which interval the disc had occurred. For the presentation on which the disc did not appear, a white matte plastic card identical to that on which the disc was drawn was used in the disc exposure field. Prior to each experimental session Ss were given several practice trials in order for them to adjust to the task and to assure the stability of the $75 \%$ baseline duration. For each of the three masking ring sizes the masking ring followed the disc at six ISI values: $0,5,25,50,75$, and $100 \mathrm{msec}$. The stimuli were presented at each ISI value in blocks of 16 trials. Six different orders of ISI presentation were used. During each experimental session 32 judgments were made at each ISI value. Six experimental sessions were conducted for each $\mathrm{S}$ yielding
192 judgments at each ISI value for each S. In addition to the above, one $S$ also was run through the same procedure using the masking ring, i.d., $36 \mathrm{~min}$, wall, $19 \mathrm{~min}$, but employing a $3-\mathrm{mm}$ artificial pupil. For all Ss under all conditions viewing was monocular. RESULTS

Figure 1 shows per cent correct forced-choice detections averaged across the two Ss in each masking ring size group as a function of ISI. The data obtained with the 3-mm artificial pupil are also shown for the masking ring size that had been employed by Kolers (1962). Analysis of variance y ielded a highly significant $(p<.001)$ effect for ISI but none of the other effects approached significance. Since there is a suggestion in the data of Fig. 1 that masking effectiveness might have varied as a function of masking ring size, an analysis of variance was performed on the data for only the 0,5 , and $25 \mathrm{msec}$ ISI values. However, even with this more sensitive analysis, the ring size effect did not approach significance $(p>.20)$.

\section{DISCUSSION}

The data we have obtained are markedly at variance with those reported by Kolers (1962). For all three masking ring sizes, including the size employed by Kolers (1962), detection errors are a monotonic decreasing function of the ISI between termination of the target disc and onset of the masking ring. Kolers (1962) had reported maximum errors at $50-\mathrm{msec}$ ISI but in our data performance is essentially $100 \%$ at ISIs longer than $50 \mathrm{msec}$. This discrepancy in results cannot be attributed to the artificial pupil since we obtain essentially the same data when an artificial pupil is employed. In fact, the shape of the masking function we have obtained is readily apparent to an $\mathrm{O}$ with only a few trials at the different ISI values.

Kolers' (1962) exposure duration of $50 \mathrm{msec}$ for the disc was appreciably longer than that employed for our Ss. However, we found that a $50-\mathrm{msec}$ exposure made the disc readily and obviously detectable $100 \%$ of the time at all ISI values.

Perhaps the discrepancy in the findings from the two experiments is attributable to the differences in the indicator methodologies employed. The modified quantal procedure employed by Kolers (1962) requires $S$ to adopt a criterion as to what he is going to report as the occurrence of the disc. What criterion $S$ adopts with this procedure is impossible to objectively determine. As the ISI between the disc and the ring is manipulated it is accompanied by phenomenal changes in perception. It is quite likely that these phenomenal changes in perception can also result in S modifying his criterion as to what he will consider the occurrence of the disc. The temporal interval forced-choice procedure employed in the present experiment avoids the problem of a fluctuating criterion on the part of S (Egan \& Clark, 1966).

If the difference between Kolers' results and ours is attributable to the differences in indicator methodology, then it would seem quite apparent that masking data obtained from experiments using objective indicator methodology cannot be integrated with data obtained from experiments where Ss were allowed to adopt their own unassessed and unassessable criterion for report.

\section{REFERENCES}

EGAN, J. P., \& CLARK, F. R. Psychophy sics and signal detection. In J. B. Sidowski (Ed.), Experimental methods and instrumentation in psychology. New York: McGraw-Hill, 1966.

ERIKSEN, C. W., \& COL LINS, J.F. Reinterpretation of one form of backward and forward masking in visual perception. Journal of Experimental Psychology, 1965, 70, 343-351.

ERIKSEN, C. W., COLLINS, J. F., \& GREENSPON, T. S. An analysis of certain factors responsible for nonmonotonic backward masking functions. Journal of Experimental Psychology, 1967, 75, 500-507.

KAHNEMAN, D. An onset-onset law for one case of apparent motion and me tacontrast. Perception \& Psychophysics, 1967, 2,577-584.

KOLERS, P. A. Intensity and contour effects in visual masking. Vision Research, 1962, 2, 277-294.

KOLERS, P. A., \& ROSNER, V. S. On visual masking (metacontrast): Dichoptic observation. American Journal of Psychology, 1960, 73, 2-21.

WEISSTEIN, N. Backward masking and models of perceptual processing. Journal of Experimental Psychology, 1966, 72, 232-240.

WEISSTEIN, N. A Rashevsky-Landahl neural net: Simulation of metacontrast. Psychological Review, 1968,75,494-521.

$$
\text { NOTE }
$$

1. This investigation was supporte; by Public Health Service Research Grant MH-1206 and a Public Health Service Research Career Program Award, K6-MH-22014. 